\title{
Career Development among Entry-Level Employees: A Case Study on Employee's in United Arab Emirates
}

\author{
Abdelkarim Fuad Kitana ${ }^{1} \&$ Asaad Ali Karam ${ }^{2}$ \\ ${ }^{1}$ Assistant Professor, Human Resource Management Department, United Arab Emirates \\ ${ }^{2}$ City University College of Ajman, United Arab Emirates \\ Correspondence: Abdelkarim Fuad Kitana, Assistant Professor, Human Resource Management Department, \\ United Arab Emirates. E-mail: a.kitana@cuca.ae
}

Received: February 2, 2019

Accepted: March 10, 2019

Online Published: April 11, 2019

doi:10.5539/mas.v13n5p13

URL: https://doi.org/10.5539/mas.v13n5p13

\begin{abstract}
Career development is an integral part of personal and professional growth of the employees, so that, the alignment of the career objectives with the roles that the new employees are playing in the organization is evaluated and analyzed to identify their individual competencies, while, as per finding of the study where finding the following factors are most affecting on individual competencies Career management competencies (CMC) with T-statistics (14.545), Goal setting competencies (GSC) with (13.834), Skill development competencies (SDC) with (13.716), which that help in deriving its influence on their career growth across a course of time is determined, however, the newly hired employees in the organization can be provided with training related to their career goals, therefore, the development of a personal goals is very important to ensure that you excel your own performance and exceed your expectations in the organization.

The results are derived by obtaining data from the participants that are the employees in different organizations in the UAE, the perspective of the new employees related to their career aspiration and the opportunity to attain them by working in their current organization is determined, moreover, The factors that the employees consider, during, selecting process is obtained in the recruitment period. It can be concluded that values, mindset, perception, vision of the employees affect their decision of selecting a company to guide their career objectives.
\end{abstract}

Keywords: individual competency, career, career development, human resource

\section{Introduction}

Changes are an integral part of growing for any organization to sustain in this evolving market driven by rapid globalization. Change in the industry can be several forms like trimming the size of the organization, restructuring, procurement of new way of doing things, installing new procedure, software, or ethics in the aim of the organization. This change instigates in the handling of the employees as they have to go through training and development, career planning and industry's responsibility increases to handle these talents (Cummings \& Worley, 2014). The progress of an individual is also dependent on the career development plan that the organizations have for their employees.

\subsection{Significance of the Research}

Growing number of organization in the market have led the industries to focus on the career development processes to sustain in the competition (Gottfredson, 2005). This made industry to focus on the personality development of the newly employed human capital and on the issues related to cross-cultural management. Human resource department started getting incorporated in the basic structure of the industry. The research is significant as most of the organizations are suffering from high employee turnover and this leads to huge losses to the organizations.

\subsection{Statement of the Problem}

The problem of employee turnover and employee motivation through incorporating career development plan and strategies related to it are the major issues covered in the study. The problem largely affects the success of the organization in its respective industry.

\subsection{Purpose of the Study}

The purpose of carrying this study is to assess the individual competencies of new employees and generate an 
efficient program to enhance the development made by them in career. The program should help them in planning about their career. The aim is to find the way to generate awareness regarding competencies among the new employees. To assess the skills of the new employee with respect to the ability to reach the organizational goals is also an objective of the report.

\subsection{Objectives of the Study}

The main objectives of the study are:

- To identify the influence of the individual competencies and the development of individuals in their career.

- To derive the parameters that help in increasing the competencies among the employees in the organizations.

- To determine skills that would improve the ability of the individuals to reach organizational goals.

\section{Literature Review}

Career of an Individual can be summed up as person's work experience at different position. The experience is reflection of the stages of life and the several positions held during the life time (Weinert, 2001). Almost 40 years back the career was simply a reflection of the work done over a lifetime (Russell, 1991). Career development start with the education of an individual, followed by counseling, followed by a choice to choose the particular job which will fall in align with educational background of the individual and the expertise developed. The choice is driven by your interests, skills, expertise, personality and values. This driving force aids the individual to be more enthusiastic and productive at your job.

There is a very vague views regarding the career as stated by (Greenhaus, 2006) Greenhaus that if an individual shifts from one field to another field, like a shift from teaching to real estate business is considered to be pursued series of careers. The recent and latest population have given a makeover to the appearance of careers is temporary, part-time, contract basis, freelance, self-employed and casual (Savickas, 2009). Hall (Hall D. T., 1996) proposed that the career of the $21^{\text {st }}$ century will be a fluctuating unit. It will be driven by the individual and controlled by the organization; this process of changing is inevitable with changing surroundings. Therefore employee turnover is a major phenomenon related with the organization's human resource development as well as it generates the need for career development. The Greek god Proteus gave birth to the term protean which represents the career of $21^{\text {st }}$ century. The name means the one who can change shape at will.

(Cascio, 2003) Cascio points out, the employees at the higher level or with higher level of expertise pursue their previously held position and experience as a badge of honor. A career consists of subjective and objective approach (Schein E. H., 1996)

\subsection{Career Development}

Career development includes several kinds of activities and processes which facilitates in enhancing different aspects tied to the career. Career development is a process which traverses in parallel with the career life cycle of an individual. Career development helps an individual to move forward and grow by learning, adapting and shifting from one surrounding from other (Brown, 2002). Several factors influence the career development processes like for example the environment at the work for employees of the organization and the satisfaction of the employee through the job.

Career planning, career management, skills, mindset are the different kind of processes or area which falls under the career development (Reardon, Lenz, Sampson, \& Peterson). It is a way to enhance the skills and knowledge that must be possessed by an individual. The individual must look to improve the skills specified to do the particular job or tasks. Development is a term which clearly reflects the changes, the growth in the structure and functions.

Career development is a growth cycle that facilitates in preparing, sustaining and advancing within a career. Career development indicates the interaction between the individual and the environment driven by cultural, economic and societal factors. After a space for job is created, career development and career planning is a perpetual process to make the individual feel contempt. Career development is also a very personal process as the individual make choices based on his knowledge, skills, priorities in life and values ingrained. The individual is solely responsible for the decision and choices taken during the career development plan. To prosper in the field of one's career three domains can be divided with according to the Bloom's domain. The three domains can be based on the personal and social traits, educational background and career management. There can two facets of the career development namely the educational learning and personal guidance coaching. Educational learning consists of developing, planning and learning from the events happening around throughout the life of an individual. The educational learning aids in knowing about the self or having an idea of own capability and expertise (Stoltz, 2013).

The educational learning facet helps in transforming the information gathered about the career into the personal 
understanding about the career. The individual should make the choice of particular career after weighing up the priorities and analyzing the impact of the career choice on the family, peers and friends. The individual gets an overall experience of the interaction with employee, mentors and trainers. It provides various sources of information which helps in searching better as well as suitable work for the individual. It teaches a way to interact and communicate with the people from different cultural background. It also facilitates in enhancing the use and understanding of the digital media platforms and several other latest technology (Bloomer \& Hodkinson, 2000).

The Personal Guidance Coaching which provides aids on a personal level to make better job choice. The individual in a way confronts to its own capabilities, aligned with self-values and desires, over any challenge, built confidence, and make right decision.

Career development indicates to work in all its scopes, facets and consequences as well as the individual's level of life. The interaction among the scopes, facets and consequences which includes for examples gender, need, ethics, health, age, demographics and environmental contexts all constitutes to assist the career development. (Van Dijk, 2004) Career development is a process to fit in the knowledgeable processes, environment and relative factor which lay down the foundation of finding the self-identity, values and ethics (Rivera, 2007). It is process of evolving and implementing concepts of life in the career. It is life-long process which includes the choices made by the individual based on the values and the compromise made by the individual when dealing with any one superior or junior. It sets the path for survival and sustaining in this world through career development.

\subsection{Job Design}

The processes like job design including the nature of job and the scope development in this design. This will have key influence over the career development as these kinds of processes are incorporated in the career development. The hiring process for the job can also be served as the process involved in the career development. Selection of potential candidates, selection criteria and how the whole process of selection is being carried out can be determined under the job selection process. Formation of smart jobs is important and this is an important factor for reintegrating the job design (Hall \& Heras, 2010).

\subsection{Human Resource}

The central human resource process of the several huge and established organization have more concrete and structure way of handling the process under the career development. The human resource initially target some potential employee then select them by passing them through different channels like the personal mentoring, campus placements, Graduate entry schemes and coaching. The medium to develop the career can also be informal like the words of wisdom received from colleagues, friends and family. These informal processes are essential and must not be ignored or taken in negative way (Hirsh, 2001).The employees need more advices to lead the development so they also depend on their own decision, desire and priorities.

Super (Super, 1980) identified five stages like growth, exploration, establishment, maintenance and decline is a kind of approach to the career development.

Sage (Hall D. T., 2002) also formulated five stages related to career whereas Schein (Schein E. H., 1978) formulate nine stages of career development. The stage where the individual searches for a job comprises the first stage called exploration. The term is clearly evident that this stage includes the research involved in the initial stage. The next stage is the period of growing in the job field by learning the skills and growing the expertise level in it. Then, maintaining the survival and sustainability of the individual which gets stable with the experience and expertise gained in the time, comes. After this stage the time to retire comes in which marks the beginning of the decline in the career development life cycle of an individual.

\section{Methodology}

The study implements a quantitative approach and the primary instruments used in gathering the questionnaire it can be a type of research design, The questionnaire distributed among the concerned employees of a particular selected organization, and the employees must clear the eligibility criteria to participate and contribute to the research, while, the employees must have experience of a minimum of 6 months and must have proficiency in reading and writing in English, due to that, the random sample was the technique to collect the data from 400 employees which are distributed randomly over all the organization in UAE.

The research design is a plan to answer the research question, A research method is a strategy used to implement that plan, while, the research design and methods are different but closely related because good research design ensures that the data obtained will help the answer of research question more effectively, that will put in order and execute research and aids to record the best results and take full advantage of the reliability of the research conclusion. Therefore, questionnaires were used to attain fitting as well as precise views of employees and 
managers.

\subsection{Limitations of the Study}

This research has opted for the questionnaire based research, this makes study equipped with some limitations also. The future researchers can learn from this limitation and can make efforts to avoid the limitation. The kind of questions constricted in the questionnaire and the data collection processes involved in the research can be counted as some limitations. In the questionnaire kind of research the problem is that there is no way to regulate the authenticity of the data provided by the employees, so the research is dependent solely on the genuine response and cooperation of the employee.

\section{Data Analysis}

The analysis of the data collected is carried through identifying the key factors and their influence on the career development strategies that are implemented in the organizations.

\subsection{Regression Analysis}

Table 1. Estimating the model

\begin{tabular}{lccccccccccccc}
\hline & & & & & \multicolumn{1}{c}{ Change Statistics } & \multicolumn{3}{c}{$95 \%$ CI } \\
\hline Model & $\mathrm{R}$ & $\mathrm{R}^{2}$ & A.R & Std. E & $\mathrm{R}^{2} . \mathrm{C}$ & F Ch. & Df1 & Df2 & Sig.F.Ch & $M(S D)$ & T.LL & T.UL \\
1 & .899 & .808 & .805 & .19263 & .808 & 275.471 & 6 & 394 & .000 & $2.39(.522)$ & 2.34 & 2.44 \\
\hline
\end{tabular}

The table represents the output of model, and it reflects the strength of the Independent variables through following factors; (Skill development competencies, career awareness competencies, scoring your career development competencies assessment, goal setting competencies, and career management competencies) on the Direct variable which is measure by multiple regressions (Entry-level employees).

The regression analysis result is a clear and striking indication on the relation between the variables; the $\mathrm{R}$ value is $89.9 \%$. The $\mathrm{R}$ value shows the concrete connection of the relationship. If the value is 1 then it shows that there is a very prominent relation between the variables. This shows that that from the numerous factors that carries a potential to have an impact on the career development, its approach involved in it, and the factors will have an influence on the decision to grab the better opportunities. The concluding result of the regression analysis can be construed as the strong relation between the Entry level employees and several predictors is relatively related with these factors. Despite having several other factors that can have an influence on career development and the choices made by the employees, these five factors play a significant role. Here the multiple $\mathrm{R}$ value is almost near 1 ; it shows that the variables have a bit more than the moderate relation to each other. The $R$ square value $\left(R^{2}\right)$ is $R^{2}=$ 0.808 . This reflects the $80.5 \%$ of variance in adoption. In other words, the majority of variation occurring in the Entry level employees is dependent on the independent variables.

\subsection{Sampling Adequacy}

Table 2. Estimating the validity

$$
\text { Kaiser-Meyer-Olkin Measure of Sampling Adequacy. }
$$

\begin{tabular}{lcc}
\hline Bartlett's Test of Sphericity & Approx. Chi-Square & 1114.801 \\
\cline { 2 - 3 } & df & 21 \\
\cline { 2 - 3 } & Sig. & .000 \\
\hline
\end{tabular}

Kaiser-Meyer-Olkin (KMO) Test is a proportion of how suited your information is for Factor Analysis. The test estimates examining sufficiency for every factor in the model and for the entire model. The measurement is a proportion of the extent of change among factors that may be regular fluctuation. The lower the extent, the more suited your information is to Factor Analysis. The (KMO) values between 0.8 and 1 indicate the sampling is adequate. The KMO values less than 0.6 indicate the sampling is not adequate and that remedial action should be taken. Some authors put this value at 0.5 , so use your own judgment for values between 0.5 and 0.6. Hence, the 
value of KMO is far enough to achieve sampling adequacy sufficient.

\subsection{Reliability Test}

Table 3. Cronbach's Alpha

\begin{tabular}{lc}
\hline Cronbach's Alpha & N of Items \\
\hline .809 & 7 \\
\hline
\end{tabular}

Test reliability alludes to how much a test is predictable and stable in estimating what it is planned to quantify. Most basically, a test is solid on the off chance that it is steady inside itself and crosswise over time. To comprehend the nuts and bolts of test unwavering quality, think about a washroom scale that gave you definitely extraordinary readings each time the researcher ventured on it paying little respect to whether the researcher had put on or shed pounds. On the off chance that such a scale existed, it would be considered not solid. Some papers also offered indications of alpha having a threshold or cut-off as an acceptable, sufficient or satisfactory level. This was normally seen as $\geq 0.70$ (five instances) or $>0.70$ (three instances) although one article more vaguely referred to "the acceptable values of 0.7 or 0.6 " (Griethuijsen et al., 2014). The alpha values were described as excellent (0.93-0.94), strong $(0.91-0.93)$, reliable $(0.84-0.90)$, robust $(0.81)$, fairly high $(0.76-0.95)$, high $(0.73-0.95)$, good (0.71-0.91).

\subsection{ANOVA}

Table 4. Means between groups of study

\begin{tabular}{cccccc}
\hline Model & Sum of Squares & Df & Mean Square & F & Sig. \\
\hline 1 Regression & 61.329 & 6 & 10.222 & 275.471 & $.000^{\mathrm{b}}$ \\
Residual & 14.620 & 394 & .037 & & \\
Total & 75.949 & 400 & & & \\
\hline
\end{tabular}

Dependent Variable: Entry-level Employees b. Predictors: (Constant), Career Awareness Competencies, Skill Development Competencies, Career Management Competencies, Scoring Your Career Development Competencies Assessment, Goal Setting Competencies, And Self-Assessment Competencies

From ANOVA table, the F value was utilized to approximate the one on one relationship between independent variables (IV) and dependent variable (DV) entry level employee. This will reflect the relationship between the independent variable and the dependent variable, like the impact on dependent value if the marks recorded by the predictors increases or decreases. Thus, the value of $\mathrm{P}$ of $\mathrm{F}$ is a sign of the implication of formed results from the provided five predictors. Moreover, from the table of ANOVA, that the P-value of F-statistic was .000 which means lesser than 0.05 , it indicates to contradict $\mathrm{H} 0$ void theory therefore, all regression coefficients stood at .000 . While, the IVs career awareness competencies, skill development competencies, career management competencies, scoring your career development competencies assessment, goal setting competencies, self-assessment competencies as the IVs P-value for each one of them is lesser than (\&1t;0.05). Hence, it indicates that the competencies namely career awareness competencies, skill development competencies, career management competencies, scoring your career development competencies assessment, goal setting competencies, selfassessment competencies paves the direction of the path for the employee's career growth in the organization. Below is the table of the coefficients of the predictors. 


\subsection{Coefficients}

Table 5. Finding the coefficients

\begin{tabular}{|c|c|c|c|c|c|c|c|}
\hline \multirow[t]{2}{*}{ Model } & \multicolumn{2}{|c|}{ Uns.Co } & \multirow{2}{*}{$\frac{\text { St.Co }}{\text { Beta }}$} & \multirow[t]{2}{*}{$\mathrm{T}$} & \multirow[t]{2}{*}{ Sig. } & \multicolumn{2}{|c|}{ Coll. St } \\
\hline & B & Std. E & & & & Tol. & VIF \\
\hline (Constant) & .058 & .080 & & .732 & .465 & & \\
\hline $\mathrm{CMC}$ & .249 & .017 & .362 & 14.545 & .000 & .787 & 1.271 \\
\hline $\mathrm{SDC}$ & .238 & .017 & .345 & 13.716 & .000 & .774 & 1.293 \\
\hline GSC & .226 & .016 & .351 & 13.834 & .000 & .759 & 1.317 \\
\hline CDCA & .075 & .031 & .062 & 2.441 & .015 & .760 & 1.316 \\
\hline SAC & .091 & .029 & .084 & 3.154 & .002 & .687 & 1.456 \\
\hline CAC & .086 & .028 & .084 & 3.117 & .002 & .669 & 1.494 \\
\hline
\end{tabular}

The table above indicates the value of $\mathrm{P}$ of $\mathrm{T}$ tests to every coefficient individually to all regression coefficients stood at (.000). Therefore, the entire independent variables were (\&lt; 0.05) have showed the noteworthy one to one relationship with the dependent variable Entry-level Employees, at a higher level. Furthermore, the table above we can observe that Co-linearity statistics since the VIF the Variance Inflation Factor (VIF) computes the correlation of Co-linearity between the variables in a regression. The Variance Inflation Factor (VIF) is 1/Tolerance, so it can always be greater than or equivalent to 1 . Hence, the outcome was indicted to reasonable Co-linearity statistics.

4.6 One-Sample Test

Table 6. Testing hypothesis

\begin{tabular}{lcccccc}
\hline & \multicolumn{6}{c}{ Test Value $=0$} \\
\cline { 2 - 6 } & & & & \multicolumn{2}{c}{$95 \%$ Conf. In.D } \\
& $\mathrm{T}$ & Df & Sig.(2-t) & Mean D. & Lower & Upper \\
CMC & 76.127 & 400 & .000 & 2.41397 & 2.3516 & 2.4763 \\
SDC & 77.899 & 400 & .000 & 2.45636 & 2.3944 & 2.5183 \\
GSC & 63.590 & 400 & .000 & 2.15212 & 2.0856 & 2.2187 \\
CDCA & 143.826 & 400 & .000 & 2.58953 & 2.5541 & 2.6249 \\
SAC & 111.739 & 400 & .000 & 2.38155 & 2.3396 & 2.4234 \\
CAC & 118.485 & 400 & .000 & 2.38204 & 2.3425 & 2.4216 \\
\hline
\end{tabular}

The One-Sample T-Test table clearly reflects inter relationship among the predictors (independent variables), from SPSS program of the entire approach has provided the ample robustness to the entire variables. Then there is TTest provides some procedures as customary like Mean, Mean standard deviation, values of $t$, values of $p$. Thus, the factor correlates with the approaches put forward, the result of approaches result has shown variety of connotation levels with all factor estimation were statistically important. Hence, to establish the statistically noteworthy height of considerable theory as were statistically significant at level (1\%). Furthermore, the OneSample T-Test result had pointed toward that all hypotheses were immensely backed by inter-relation between the predictors. In addition, the study has projected adequate respondents size of 349 , and it indicates to sufficiently apt data that were accumulated during the research and the analysis followed by it.

\section{Discussion}

Career development is a lifelong procedure; an individual commences his career with the attainment of good educational qualifications, on completion of education, he has to select an appropriate employment opportunity or job or a relevant source of income in order to earn his living. There have been several career opportunities and there has been emergence of abundant areas such as law. An individual starts his career by getting enrolled into an 
institution and a program of his choice, in accordance with his needs and abilities. A bright individual who has secured good grades in high school sometimes gets confused regarding which field he should select, in that case, he seeks advice and help from a career counselor, who assesses his needs, abilities, strengths and weaknesses and then guides him accordingly towards the right path.

Different people, for example, guardians, relatives, companions, profession advisors are there to control, guidance, help and lead the person the correct way, yet it is totally up to the person to choose what he needs to accomplish, what he needs to end up, what are his necessities and what sorts of qualities and capacities does he have. It is fundamental for the person to create profession the executives aptitudes, so as to make an effective vocation, it is basic for the person to build up his abilities and one of the aptitudes improvement strategy happens through professional preparing; professional preparing is conferred through different plans and these have been looked into and staff preparing, ladies preparing, instructional material advancement, progressed professional preparing plan, Hi-tech preparing, apprenticeship, experts preparing plans, etc. In any sort of an association, organization or an establishment, it is important to build up certain initiative aptitudes so as to achieve profession improvement in a fruitful way, the fundamental authority abilities are rousing individuals, having powerful correspondence and capacities to settle on fitting choices.

In one's improvement of vocation prospects, an individual typically experiences different sorts of hindrances, these can be money related issues, low capacities levels, and abilities; some of the time in immature districts or territories, an individual can't obtain essential instruction because of number of issues, for example, family issues, budgetary issues, expansive separations, absence of proper methods for transportation, etc. At the point when an individual isn't accomplished, he will absolutely confront obstructions in the advancement of his profession prospects and keeps on functioning as a worker or get occupied with some sort of a minority work; this is as yet common in country and additionally urban parts of India. Inside the associations, vocation improvement is viewed as a basic idea and there have been sure focuses that feature the noteworthiness of profession advancement, for example, considering profession improvement as the fundamental need, having better preparing, apparatuses and abilities, better self-appraisal, individualized training and gathering sessions and estimation of rate of return. At long last, it tends to be expressed that profession advancement ought to be considered as the principle need and every one of the people ought to be equipped towards the enhancement of their capacities, aptitudes and ability in such a way, to the point that could prompt successful vocation improvement.

The research found that it is necessary for the employee to be aware of the subject of the profession he is seeking and what is the future of this profession and whether it suits his skills as well, this could be by opening consulting centers, In addition to the functional goals that the person sets for himself and through which he seeks to achieve these goals through the development of efficiency and skills and the way of performance, As well as the employee in the beginning of his work and in a new work environment needs to develop his skills commensurate with the nature of his job, which corresponds to the qualifications to be able to progress in the career path and also changes the behavior of the employee when he engaged in the work environment and begins to understand the organizational culture of the organization in addition to initial training and often change behavior UAE employee after 6 months of commitment.

The UAE employee also seeks good salaries and often chooses government institutions instead of the private sector because the government has better incentives and salaries than the private sector. A very important point for each functional is what KSAO; is an acronym for Knowledge, skills, abilities and other characteristics. They are extremely helpful for recruiting personnel. KSAOs describe the skills and attributes required for a particular position in an organization for example the can gets through training. In addition to the outputs of the good education gets the knowledge and in the beginning of the work acquire more abilities and knowledge and skills and develops over time and through it can progress in the job, also worth mentioning without KSAOs cannot progress and develop in his career and career path so the staff To understand these things and know the culture and reputation of the organization because it helps them in their career development they need to scanning / skimming and ask before they accept the job offer by entering the organization's website and asking the old employees as well as tools and new tools that help them to develop their career.

\section{Conclusion}

There have been plethora of study, research on the accurate and precise definition of the term Career. The career is a term which in a nutshell describes the entire life cycle of an employee by keeping the track of progression and regression involved in the entire cycle. Many employees gets successful in striking the successful career progression and even more crumbles in the respective field, the career development is an amalgamation of several process which involves career planning, experiencing the work, human resource, promotion and many more. 
The career development is driven by factors like the values and mindset of the employees, the certain arrays of skill the employee possess, the employees' ultimate goal or aim in life and the satisfaction enjoyed the individual in the environment provided by the organization. In this research paper to understand the factors affecting career development a questionnaire was prepared and was distributed among the employees of an organization and their responses were recorded. Then a regression analysis was made from the results from the recorded response based on one dependent value which was entry level employee and the five independent values based on the selfdevelopment, skill, goal, awareness and career development kind of competencies. This analysis showed a strong relation between the independent and dependent variables which makes it evident that the new level employees should possess a certain level of skill set and awareness regarding the job.

\section{References}

Bloomer, M., \& Hodkinson, P. (2000). Learning careers: continuity and change in young people's dispositions to learning. British educational research journal, 26(5), 583-597.

Brown, D. (2002). Career choice and development. John Wiley \& Sons.

Cascio, W. F. (2003). Changes in workers, work, and organizations. Handbook of psychology, 12, 401-422.

Cummings, T. G., \& Worley, C. G. (2014). Organization development and change. Cengage learning.

Gottfredson, G. D. (2005). Career development in organizations. Handbook of vocational psychology, 3, 297-318.

Greenhaus, J. H. (2006). Encyclopedia of career development. California: Sage Publications.

Hall, D. T. (1996). The new protean career: Psychological success and the path with a heart. The career is dead: Long live the career, 15-45.

Hall, D. T. (2002). Careers in and out of organizations (Vol. 107). California: Sage publications.

Hall, D. T., \& Heras, M. L. (2010). Reintegrating job design and career theory: Creating not just good jobs but smart jobs. Journal of Organizational Behavior, 31(2-3), 448-462.

Hirsh, W. J. (2001). Straight talking: effective career discussions at work. Cambridge: National Institute for Careers Education and Counselling.

Kothari, C. R. (2004). Research methodology: Methods and techniques. New Age International.

Neuman, W. L. (2013). Social research methods: Qualitative and quantitative approaches. Pearson education.

Reardon, R. C., Lenz, J., Sampson, J., \& Peterson, G. W. (n.d.). Career development and planning: A comprehensive approach. 1999: Wadsworth Publishing Company.

Rivera, L. M. (2007). The effects of perceived barriers, role models, and acculturation on the career self-efficacy and career consideration of Hispanic women. The Career Development Quarterly, 56(1), 47-61.

Russell, J. E. (1991). Career development interventions in organizations. Journal of Vocational Behavior, 38(3), 237-287.

Santos Jr, E. (1999). Probabilistic temporal networks: A unified framework for reasoning with time and uncertainty. International Journal of Approximate Reasoning, 20(3), 263-291.

Savickas, M. L. (2009). Life designing: A paradigm for career construction in the 21 st century. Journal of vocational behavior, 75(3), 239-250.

Schein, E. H. (1978). Career dynamics: Matching individual and organizational needs (Vol. 6834). Boston: Addison Wesley Publishing Company.

Schein, E. H. (1996). Career anchors revisited: Implications for career development in the 21 st century. Academy of management perspectives, 10(4), 80-88.

Stoltz, K. B. (2013). Applications of motivational interviewing in career counseling: Facilitating career transition. Journal of Career Development, 40(4), 329-346.

Super, D. E. (1980). A life-span, life-space approach to career development. Journal of vocational behavior, 16(3), 282-298.

Van Dijk, M. S. (2004). Career Development within HRD: Foundation or Fad?. Online Submission.

Weinert, A. B. (2001). Psychology of career development. International encyclopedia of social and behavioral sciences, 1471-1476. 


\section{Copyrights}

Copyright for this article is retained by the author(s), with first publication rights granted to the journal.

This is an open-access article distributed under the terms and conditions of the Creative Commons Attribution license (http://creativecommons.org/licenses/by/4.0/). 